\title{
Theory- and Evidence- Based Intervention: Practice-Based Evidence - Integrating Positive Psychology Into a Clinical Psychological Assessment and Intervention Model and How to Measure Outcome
}

\author{
Poul Nissen \\ University of Aarhus, Copenhagen, Denmark
}

\begin{abstract}
In this paper, a model for assessment and intervention is presented. This model explains how to perform theoryand evidence- based as well as practice-based assessment and intervention. The assessment model applies a holistic approach to treatment planning, which includes recognition of the influence of community, school, peers, family and the functional and structural domains of personality at the behavioural, phenomenological, intra-psychic and biophysical level in a dialectical developmental process. One important aspect of the theoretical basis for preparation of this model is that the child's personality must be understood in terms of the historical development. This assessment and intervention model focuses equally on strength and virtues as well as obstacles against development within the individual and its relations. Finally, guidelines for how to measure outcome are provided.
\end{abstract}

Keywords: assessment, evidence-based, theory-based, practice-based intervention, positive clinical psychology

\section{A Dialectical, Psycho-relational Perspective on Development}

The PRAIM (Psycho-relational Assessment Intervention Model) has been developed to be used for children and adolescents with more or less arrested identity development where a goal-oriented approach is needed. The term "assessment" was chosen over examination, in order to underline that an appraisal of the collected data in which the interventions are based takes place. It is also an integrative model, because it is not based on a single theoretical approach, but allows several theoretical approaches in accordance with the particular task at hand.

There are many models and theories concerning children's and adolescents' psychopathological development from bio-physical, psychodynamic and cognitive to social psychological, systemic and sociological models. The aforementioned emphasizes an individual perspective on development and the latter emphasizes the importance of the relations. The model that will be presented here attaches importance to both the relations and the individual, therefore, the term psycho-relational was chosen. By choosing the term "psycho-relational” instead of "psycho-social", it emphasizes that the human psyche relates to both ideal and material objects. The model is firstly thought as a working tool in connection with children and adolescents, but it can also be used with grown-ups.

Poul Nissen, Ph.D., associate professor, DPU, University of Aarhus. 
The psycho-relational model is based on the assumption that representations of generalized interactions, object- and self- representations (Kernberg, 1996) or schemata (Pretzer \& Beck, 1996) contribute to conducting the actions within the relations the child enters into, and also that the relations the child interacts within (Sroufe, Duggal, Weinfield, \& Carlson, 2000) contribute to the development of generalized interactions, object- and self- representations or schemata. It is within this dialectical reciprocal interaction that children's and adolescents’ psycho-relational development takes place over time (Sameroff, 2000).

This developmental process can be examined at several levels (see Figures 1 and 2): a behavioral, phenomenological, intra-psychic and biophysical level (Millon, 1999; Millon \& Davis, 1996).

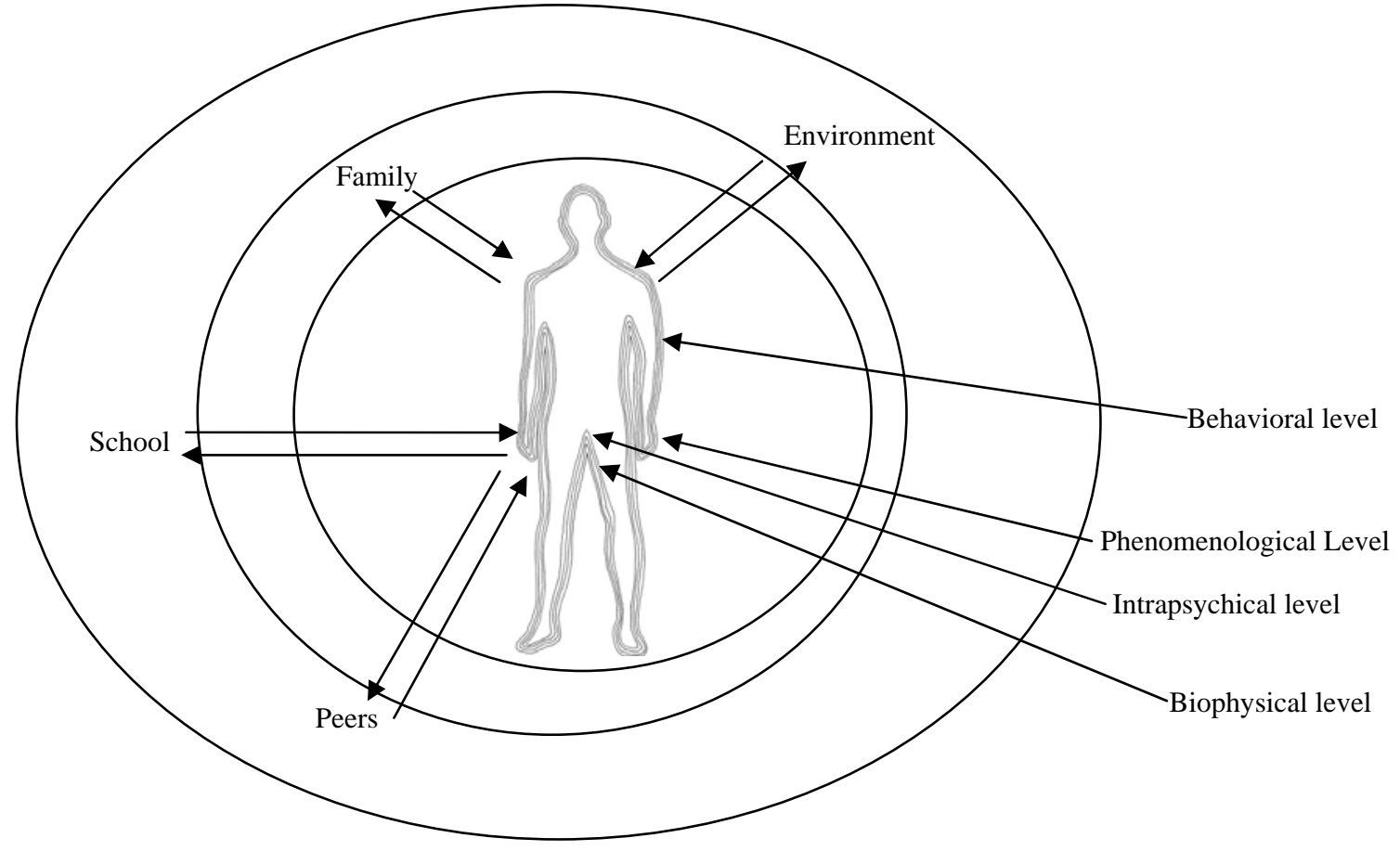

Figure 1. Assessment and intervention model.

At the behavioral level, how a person behaves and affects others is indicated. At the phenomenological level, characteristics of the cognitive style, self-image and object representations are indicated. The intra-psychic level is characterized by coping strategies or defense mechanisms and structural and functional aspects of the personality. At the biophysical level, physical and biological features are indicated. These four domains of the personality structure and function are seen in a relational interplay among environment, family, peers and school.

As seen in Figure 1, the biophysical level encompasses somatic matters, genetics, neurobiology, as well as inherent properties, such as temperament. The intra-psychic level encompasses the morphological organization, which are the structural strength, interior congruity and functional efficacy of the personality system. At this level, one also finds defense mechanisms or coping strategies. At the phenomenological level, one finds psychic structures and functions as object- and self- representations, self-image, and immature defense mechanism or coping strategies. The term "phenomenology" alludes to the phenomenon that appears in the brain of the child or the adolescent as the world emerged for them, who perceive and experience it. Object representations are early internalized representations of significant others and inner imprints of early 
experiences, i.e., the influence of the parents and other significant people during childhood. At this level, we also found the self-image has been developed during childhood. The self-image is comprised of the swirl of events that buffets the young child to a growing sense of "I" or "me" or self-identity. The cognitive style was also found here, i.e., how the child conducts his attention, processes and mediates impressions.

\begin{tabular}{|c|c|}
\hline Functional domains & Structural domains \\
\hline \multicolumn{2}{|c|}{ Behavioral level } \\
\hline \multicolumn{2}{|l|}{ Expressive acts } \\
\hline \multicolumn{2}{|l|}{ How the person acts } \\
\hline \multicolumn{2}{|c|}{ What the person unknowingly reveals } \\
\hline \multicolumn{2}{|c|}{ What the person wishes us to think or know } \\
\hline \multicolumn{2}{|c|}{ Interpersonal conduct } \\
\hline \multicolumn{2}{|c|}{ A person’s style of relating to others } \\
\hline \multicolumn{2}{|c|}{ How the person's actions impact on others } \\
\hline \multicolumn{2}{|c|}{ Methods by which he/she engages others to meet his/her needs } \\
\hline \multicolumn{2}{|c|}{$\begin{array}{cc} & \text { Phenomenological level }\end{array}$} \\
\hline Cognitive style & Object representations \\
\hline How to allocate attention & Inner imprints of early experience \\
\hline How to organize thoughts & Internalized representation of significant others \\
\hline \multicolumn{2}{|l|}{ How to process information } \\
\hline \multicolumn{2}{|l|}{ Self-image } \\
\hline \multicolumn{2}{|c|}{ The swirl of events that buffets } \\
\hline \multicolumn{2}{|c|}{ The way to a growing sense of "I" or "me" } \\
\hline \multicolumn{2}{|c|}{ Development of self-identity } \\
\hline \multicolumn{2}{|c|}{ Intra-psychic level } \\
\hline $\begin{array}{l}\text { Regulatory mechanisms } \\
\text { Mature }\end{array}$ & $\begin{array}{l}\text { Morphological organization } \\
\text { The structural strengths and functional efficacy of the } \\
\text { personality system }\end{array}$ \\
\hline \multicolumn{2}{|l|}{ Intermediate } \\
\hline \multicolumn{2}{|l|}{ Immature } \\
\hline \multicolumn{2}{|c|}{ Biophysical level } \\
\hline & Mood/temperament \\
\hline & Affect \\
\hline & Expressive features of mood \\
\hline & Level of activity \\
\hline
\end{tabular}

Figure 2. Functional and structural domains of personality. Source: Millon and Davis (1996) and Millon (1999).

The two functions of the personality structure are indicated at the behavioral level (see Figure 2), such as the kind of actions that the child or the adolescents express, which characterize the interpersonal conduct. The first mentioned refers to the way the child or the adolescent conducts oneself, acts or unknowingly reveals and what the child or the adolescent would like us to think or know about it. The interpersonal style particularly refers to how the child or the adolescent relates to others, how their actions impact others and methods by which he or she engages others to meet his/her needs.

Meanwhile, the child or the adolescent takes part in a number of relational systems: family, school, peers and immediate environment (see Figure 1), and these systems, thus, respond to the behaviors of the child or adolescent. These behaviors influence the acts of the child or the adolescent and these acts produce new phenomenon that will settle at the intra-psychic level over time and may be somatic symptoms at the 
bio-physical level. In that way, children's and adolescents' psycho-relational development can be seen as a dialectical developmental process over time, by which the impact of the relations effects the development of the personality structure and function, which again has an impact on the relations of the individual.

To illustrate this, we could consider a young person with trisomy 21 (Down's Syndrome), for whom the syndrome's development and level of complexity previously mainly was thought of as determined by genetic factors, but now the environment is also considered as a vital influence on the developmental course. At the bio-physical level, a side from the abnormal 47 chromosomes, there are structures that predispose development of myocardial infarct and blood clot in the brain (Reichler \& Lee, 1987). At the intra-psychic level, the morphological organization will be compromised, whereas coping strategies or defense mechanisms may be average or immature. At the phenomenological level, the cognitive style will be compromised (retardation) and maybe even the self-image and the object representations, depending on conditions during childhood. Some people with Down's Syndrome may have difficulties that relate to the object representations in terms of part-object and part-self representations, i.e., the self is not integrated (Kernberg, 1996), and thereby the structure and function of the personality is disordered. At the behavioral level, the person might behave as friendly and happy in order to appear as normal as possible. People with Down's Syndrome appear different from other people, so the environment will respond differently to people with 46 chromosomes. During school, there will be situations that will remind a person with Down's Syndrome that something is wrong (e.g., the use of other textbooks and instructions than with other students), and the identity development will have different opportunities for socialization, such as soccer clubs, discotheques, etc., in terms of exclusion instead of inclusion. These impressions will alter the person's behavior and the phenomena in the brain in the long run, settle within the intra-psychic structure and function and maybe also cause bio-physical somatic symptoms and again produce acts that have an impact on the relational system.

\section{The Development Through Childhood}

The dialectical model outlined above, must be based on a psycho-relational development perspective, from conception to the here-and-now situation. It is widely agreed that the childhood is of great importance for the personality development of children and adolescents, but disagreements exist that whether children during childhood go through phases (Kernberg, 1996; Mahler, 1975, 2000), stages of development (Erikson, 1950/1963) or altering positions (Klein, 1932; 1975). It is also disagreed about when the self is developed. For example, Stern (1985) believed that it occurs very early, while Kernberg (1996) believed that it occurs later.

This model for children's and adolescents' psycho-relational development is devised so that childhood is not divided into phases, positions or stages of development, but in age periods, thus the different theoretical perspectives can be utilized on information about the psycho-relational development (see Figure 3).

\section{Outline of the Assessment Process}

Figure 4 provides an outline of the assessment process. It is indicated at the left bottom of the figure that relational data and data from the personality structure and functions as well as the historical development are collected. It relates to data concerning both areas of strength and problem areas. Hereby a matrix of information is obtained, which gives rise to reflections at a theoretical level and comprises integration of theory, research evidence and clinical expertise. That is, at this level, theoretical considerations are supplied, which may contribute to explain practice and the gathered statements. These theoretical considerations give rise to 
hypotheses about, to what extent the identity development is fixed or not, and intervention suggestions are composed based on these hypotheses.

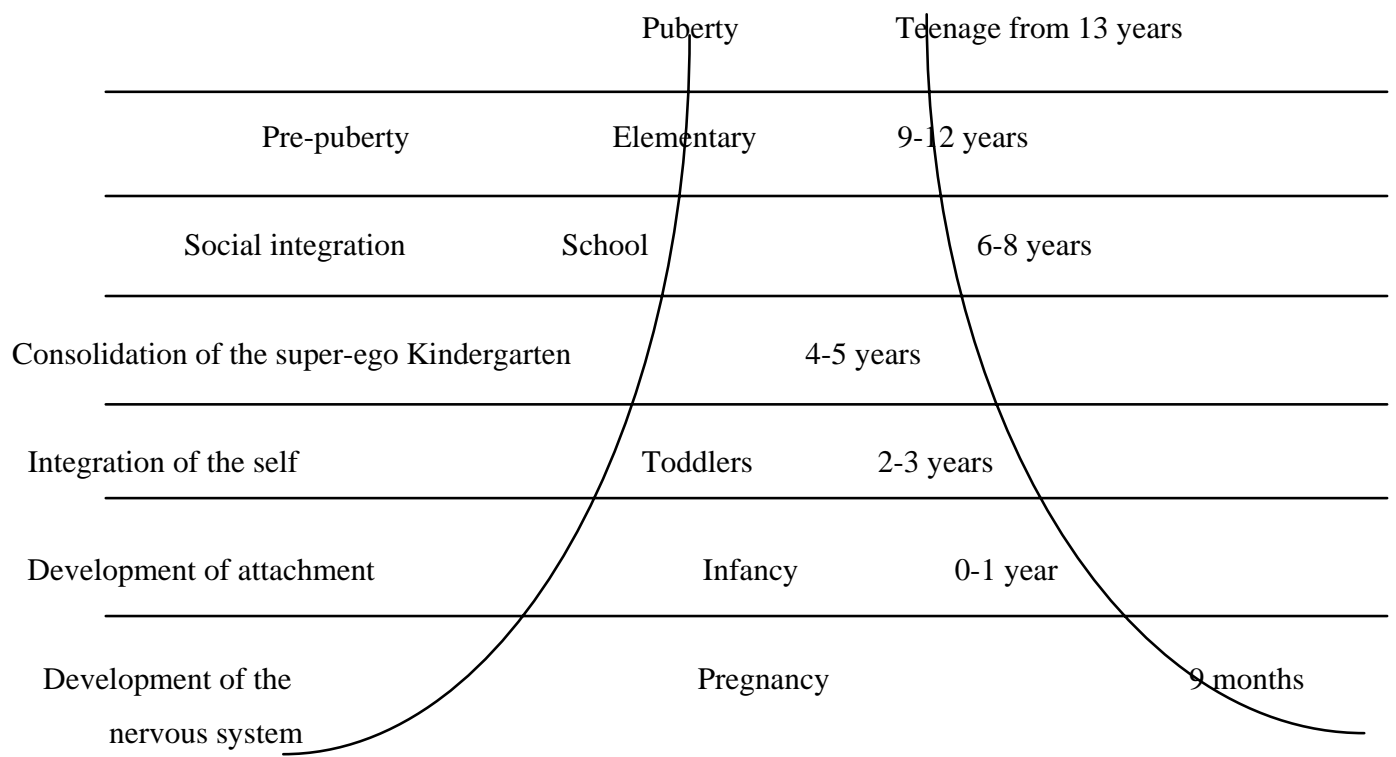

Figure 3. Age distribution of the development history.

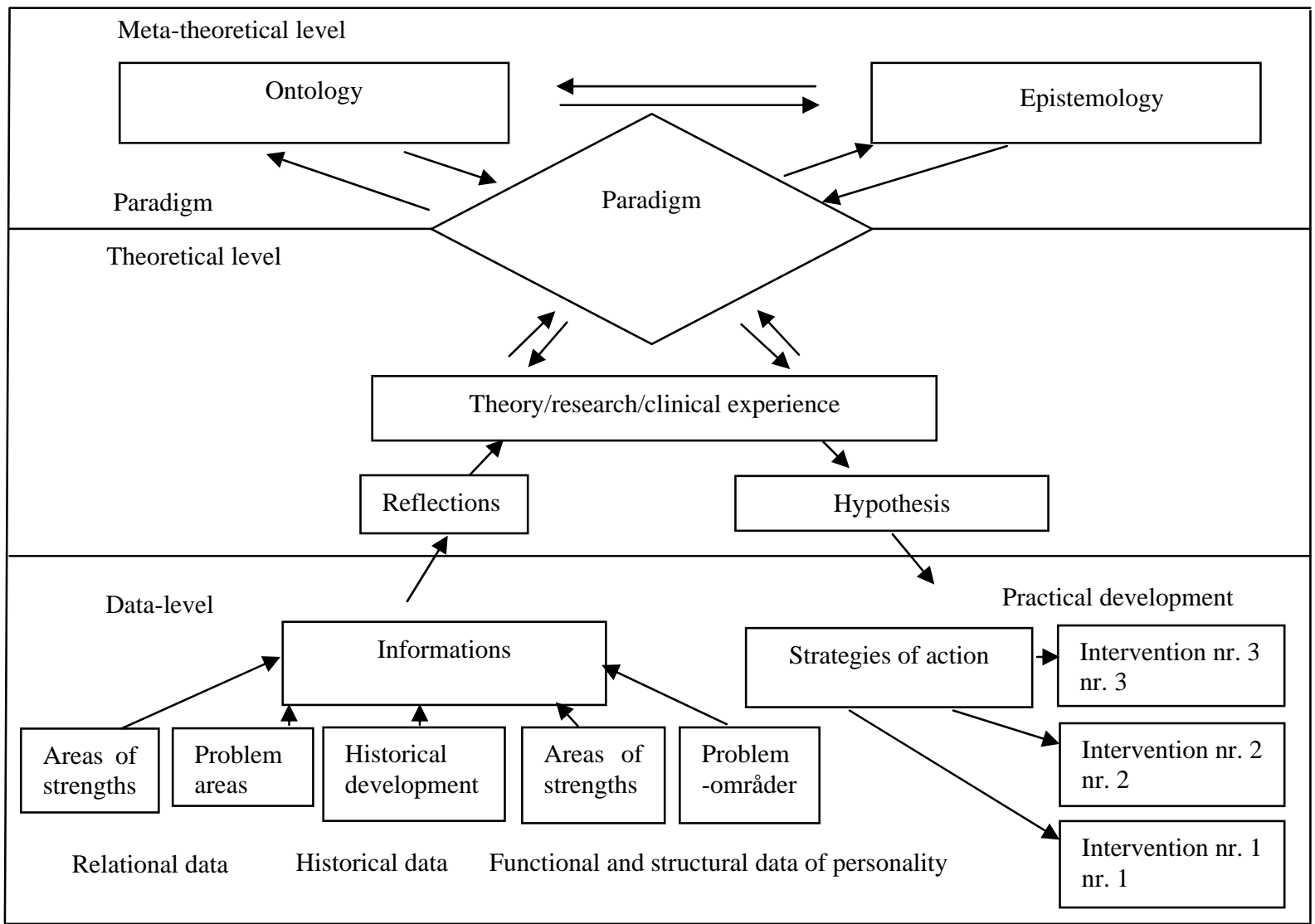

Figure 4. Overview of the dialectical process of elaboration of assessment and intervention.

At the top of the figure, a meta-level is indicated, based on the notion that ontology, epistemology and 
paradigm affect the choice of theory and the dialectical process that is indicated on the data and theory level. Hence, a diagnosis in the traditional sense is not the aim, but rather a snapshot combined with the theoretical/research/clinical expertise-based interventions, which then are executed in practice, whereby new relational, historical and personality structural and functional data arise. As shown in Figure 4, data from both the problem and strength areas of the person are collected.

In the book Assessment \& Intervention Guide (Nissen, 2007), a number of guiding questions were indicated. These questions will be used when we collect data from the four domains of relations and the four levels of personality structure and function. These eight areas can furthermore be supplied with relevant tests, such as Achenbach's (2009) questionnaires, which can tell us even more about the behavioral and phenomenological levels. WISC-IV (Wechsler Intelligence Scale for Children) (Wechsler, 2003) and Rorschach (Rorschach Inkblot Test, Exner, 2003) can highlight the cognitive function. The intra-psychic level can furthermore be clarified by, for example, TAT (Thematic Apperception Test) (Westen, 2000) and Rorschach (Rorschach Inkblot Test, Exner, 2003) and the parental manner by help from Parents Preference Test (Westh, Ferrer, Prieler, \& Hartmann, in press) just to mention a few examples.

\section{Psycho-relational Analysis, Assessment and Intervention}

After having collection of the historical development data (see Figure 3), as well as relational and personality structural and functional data, a psycho-relational analysis is undertaken (see Figure 5), which is an analysis of the strengths/resources and obstacles in the surroundings and obstacles in the personality. Which conditions in the surroundings and personality contribute to a standstill in development, and which strengths and resources can be mobilized in the surroundings and personality? Hereafter, an assessment and interpretation of the collected data (see Figure 4) was carried out. Meaning that based on a series of data, a range of information emerges, which gives rise to hypothesis that can be converted into strategies of action and practice based interventions (see Figure 4).

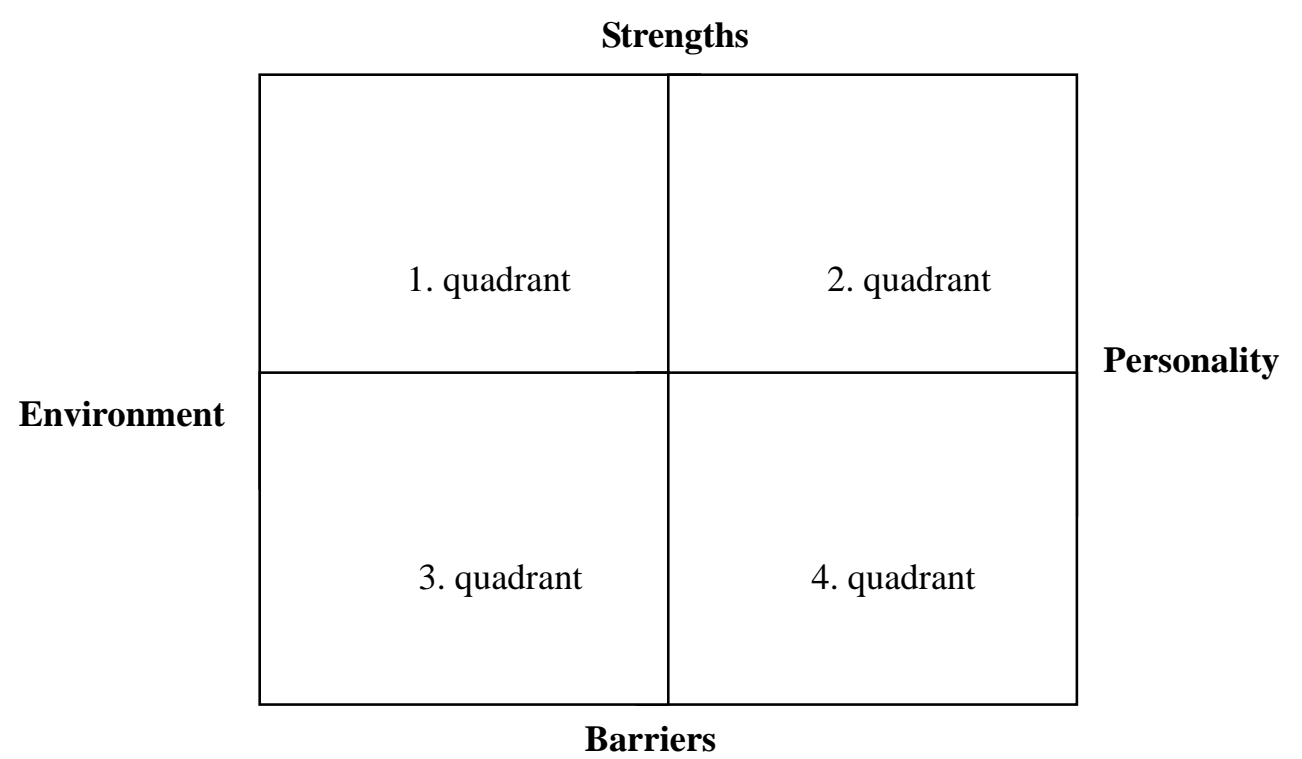

Figure 5. Identification of resources and barriers for development within personality and environment.

If the assessment reveals difficulties with the cognitive style, then cognitive therapy can be a relevant 
course of action, and if there are difficulties with the object representation or the self-image, approaches based on respectively, object relations theory (Kernberg, 1996; Kernberg, Weiner, \& Bardenstein, 2000) or self-psychology therapy (Glasser \& Wubbolding, 1995; Kohut, 1971, 1977; Raskin \& Rogers, 1995; Stern, 2000) may be of relevance.

\section{Illustrated Example of the Model—Lucas}

The model can be used to solve individual tasks, where a professional composes suggestions for intervention, but it can also be used at, for example, a care center, where several professionals work together to compose strategies of action and intervention. For instance, social workers, psychologists, teachers and social education teachers can collect historical, relational and personality structural and functional data (see Figure 4) and present these findings at a treatment conference, then jointly reflect over these findings in a theoretical research-based perspective and supplemented by clinical experience, and present hypotheses on which strategies of action and intervention base. Lucas, in the following section is a case from a care center, where the members of staff cooperate to collect data, carry out assessment and propose strategies of action and interventions.

\section{Lucas}

Historical development. Lucas' mother informed one of the care center workers that she grew up with her mother who was single, and she never knew her father who was from Sweden. Her mother was the owner of a kiosk and Lucas' mother spend much time there in early years. All though Lucas' mother was busy, she had the feeling of a pleasant upbringing. After the tenth grade, she spent a couple of years not doing much, but then she got an education as a social and healthcare assistant. Subsequently, she has had two periods of maternity lives giving birth to two girls with different fathers. In between, she worked in retirement homes and has been on sick lives due to a bad back and knees and stress. Lucas's mother met shortly Lucas's father, who was from Iceland. They did not live together and he left Denmark and went back to Iceland at the end of the pregnancy. Lucas's mother gave birth to Lucas and she reported that the pregnancy was uncomplicated in the beginning, which was also evident of the journal from the hospital. However, Lucas' mother was referred to a midwife in the 33th pregnancy week due to a weight increase of $32 \mathrm{~kg}$ and expressed discomfort of universal edema.

The mother stated that it was a difficult birth which lasted two days, and Lucas had to be delivered by suction in the end. He weighed 3,500 g at birth and was $50 \mathrm{~cm}$ long. The medical journal from the hospital shows that the mother suffered from pre-eclampsia and that the boy was weak and blue at birth ${ }^{1}$, but there were no evident deformities and he was otherwise a healthy boy. As a baby, Lucas was according to the mother very active and did not require much sleep. He was breastfed for a month and was thereafter given the bottle since there was no more milk. According to the hospital and mother, Lucas continuously suffered from ear inflammation $^{2}$. The mother reported that she stayed at home during the first year before Lucas went to daycare. According to the mother, it was a very good daycare center with a child care worker that had a good understanding of children and where Lucas thrived. After daycare, Lucas went to a kindergarten, where the kindergarten teachers did not understand Lucas's needs, and at the age of four years, he was referred to a psychological examination because of behavioral problems, since the kindergarten teachers believed he was

\footnotetext{
${ }^{1}$ Apgarscore 6/1, 9/5, 10/15. From the birth journal it appears that Lucas shortly after birth develops hyper bilirubinaemi which is consecutively treated with light treatment, since Lucas becomes weak. Bilirubin increases despite single light, hereafter double light where bilirubin decrease.

${ }^{2}$ Was treated with ear tubulation.
} 
particularly aggressive towards other children. The psychological examination showed that Lucas was delayed in development. Moreover, the examination showed that Lucas was very knowledgeable and he was able to deduce wider terms. His knowledge appeared to be rather mechanical though he may lack an understanding of certain meanings in the language. He had difficulty in maintaining emotional information which is primarily verbal. It made him emotionally frustrated in linguistic contexts, in which acting out is seen. When he was about five years old, Lucas went to the hospital for a diagnosis because his mother believed that his difficulties were related to him being temporarily oxygen deprived at birth. The examination showed that the delayed development and behavioral difficulties were more likely caused by family predispositions and upbringing issues in the home than oxygen deprivation. At age six, he was referred by his own doctor under the diagnosis of bed wetting, general challenges to development ${ }^{3}$ and hyper-kinetic behavioral disruption. The doctor treated Lucas medically ${ }^{4}$, but without any effect. Additionally, the mother would like to counsel on how to deal with Lucas when he acted out, but the doctor referred to counseling center, which they felt provided excellent counseling.

At age six, Lucas was placed in a special class for children with various handicaps including conduct disorders. During this period, he was placed with a relief family every other weekend. Lucas did not like being in this family because he was used as a babysitter for other children. The mother was also dissatisfied with this arrangement and tried a new relief family, but difficulties also arose here, where after the arrangement was terminated. At that time, Lucas's mother moved in with a man the two smaller siblings calls father, but not Lucas.

At age 10, Lucas changed schools and was placed in a normal class with support where he stayed until the 6th grade. Hereafter he was placed in another school with a similar offer. According to Lucas and his mother, he was constantly bullied by other children at this school. The journal pages showed that at this time, the stepfather left the home that was violent for a long time. During this time, Lucas had told one of the teachers about the difficulties at home and talked about taking his own life. This results in the municipality undertaking massive efforts in the form of a contact person and MST (Multi-systemic Therapy). Despite of these efforts, Lucas was still not thriving and sought contact with adults outside the family. Hereafter the mother wished Lucas to be placed outside the home and he was, thus, placed in a care facility.

\section{Relational Description}

Immediate environment. The care facility is located in a rural area by the sea and close to a small town in an urban environment with shops, restaurants, cafes and taverns, pizzerias, club and society life, schools, indoor public swimming pool, school and clubs, which also held parties and courses where the youth can get a scooter or a tractor license. Close to the care facility are excellent boating and fishing opportunities, and the facility owns a rowboat. A small number of animals are also kept at the facility. The facility is surrounded by a forest where pheasants and deer live. The facility has a good contact with neighbors, which include practical assistance and participation in each other's daily lives and routines.

The facility has room for four 24-hour students and each student has their own room with an optional TV and computer.

The facilities' youth and children have access to computers in common areas. The students are encouraged to take part in renovation and decoration of their own rooms, which Lucas did in the form of new decor and new furniture. The facility has a live-in staff, a married couple, who has worked within this field for years and

\footnotetext{
${ }^{3}$ Retardation psychomotorica.

${ }^{4}$ Minirin.
} 
lived side by side with the youth.

School. Lucas attended a local school, where he was well received in a special needs class. The academic subjects were taught individually, and Lucas worked well. Sometimes, the class was split up into smaller groups in the subjects of home economics, physical education, history and social science. Movies were frequently used in history class, and in social science, various subjects like violence and addiction were often discussed. Lucas often offered insight and opinions on the issues at hand, according to the teacher. Moreover, Lucas partook by choice in a traineeship with the aim of which was to figure out how society works. There were nine students in the class and four to five teachers were affiliated with the class. The teaching was dominated by social learning and the traineeships were aimed to prepare students for employment. Lucas got up early every day and took the bus to school. There was regularly contact between the school and the care facility.

Friends. Another boy, Amir, lived at the care facility. Lucas had a friendly relationship with him. They were together daily, took walks in the forest, shared common experiences and interest, and often spent time together by the computer or in the rooms, but they had very different abilities and areas of interest. Amir often picked up Lucas by the school bus in town. Other than Amir, Lucas had a few acquaintances in vicinity, which included friendship-like relations to several social workers from the local area (school, police and recreational clubs). Lucas had frequently changed "girlfriends", with whom who he was in contact on the Internet (net-dating), but whom he never met in person. Similarly, there were a lot of contacts through texting. In the friendship with Amir, Lucas often stetted the agenda. The relation to Amir is characterized by initiative more than by a mutual, balanced and involved give-and-take relationship.

The family. The mother currently lived in an apartment with three bedrooms. The mother showed the apartment where there were holes in the doors where Lucas had kicked in the doors during temper tantrums. Lucas had a younger sister, who was one year younger than Lucas and who like Lucas, placed outside the home, due to behavioral difficulties. The mother now lives alone with the youngest sister, who goes to a normal school. Lucas's stepfather has taken up employment abroad and Lucas has not seen him since the divorce. There is no connection with Lucas's biological father. The mother once more worked as a social and healthcare assistant in the municipality, but with less strenuous work than at the retirement home. The communication between mother and son was characterized by the mother being compelled to change their arrangements, which contributes to conflicts and anger. On the other hand, Lucas also altered the agreements after conflicts or misunderstandings. Lucas's mother has expressed relief with Lucas being placed outside the home, because it left her time to care for the youngest child.

\section{Personality Structure and Function}

Behavioral level. According to the adults at the care facility, Lucas displayed a great sense of responsibility when it came to practical tasks, if he knew the task at hand and how to perform it and if there was some sort of personal gain besides acknowledgement. According to the mother and former teachers' reports of arson, theft and vandalism in which Lucas has taken part in the past few years, Lucas was said to be lacking internal locus of control in open social situations, where he could get carried away, unlike structured situations where aims, implementation and method were known and where Lucas functioned well. The give-and-take process in the convergent, social relations, such as where food is prepared, animals are fed, or where transport work is undertaken, the assignment is, thus, clearly defined, and is characterized by reciprocity and balance.

The give-and-take process in the divergent, social relations, where aim and mutual expectations arisen a 
long the way with several options and where the activities were creative and unpredictable, is where Lucas adjusted to the partner, argued his point of view and changed the subject. In his relationship to Amir, Lucas liked to control the situations. In his relation to adults, Lucan could tease and joke about at friendship level and provoke or kid around at a more neutral level. The care facility experienced a fair amount of aggression management, where fair agreements are changed. The mood is experienced to be slightly forced. Lucas sometimes spoke with a very loud when he was pressured. Lucas was said to be non-critical in the establishment of contacts to people in his surroundings. Lucas, his mother and teachers reported more difficulties than normal for boys at Lucas' age ${ }^{5}$. The issue at hand is both the internal behavior, such as being anxious/depressed, and complaints of pain and thought problems. Lucas' mother furthermore reported several other difficulties of externalizing behavior than what is normal for the age ${ }^{6}$, such as rule-breaking behavior and aggressive behavior, and destruction of own and his family's items. Lucas's teachers, however, did not report of aggressive behavior that what is normal for the age. However, the teacher reported several difficulties of rule-breaking behavior as the mother does, than what is normal for the age ${ }^{7}$. Lucas seemed to lack remorse and lay or cheated when given the opportunity. The teacher and the mother both reported more difficulties that what is normal for the age in relation to social or thought problems, such as teasing, stories which do not seem to be in touch with reality or a high degree of dependence on adults. In relation to the adaptive function in school, the teacher assessed Lucas' efforts in four subjects to be far below the average and in one subject to be below average, while his behaviors and mood was above average compared to what is typical for students at Lucas' age. The mother's assessment of Lucas' competence in connection with social activities and academic performance was below what one expects of boys at Lucas's age ${ }^{8}$.

Phenomenological level. In relation to competence with social activities and performance in school, Lucas assessed himself to be within the normal range. This also applies to problem areas, such as anxiety/depression, isolation/depression, somatic complaints, social problems, thought problems, attention problems and rule-breaking and aggressive behavior.

Lucas furthermore expressed that he often felt tense which resulted in several forms of physical discomfort and somatic difficulties. He was to some extent wary of others and he expressed that over the years others have spied on him. Sometime, he felt like there was someone close to him, which came to him having specific thoughts that appear again and again in his head. Lucas felt that he was a very sociable and outgoing person; he did not settle for being a bystander when he was attending a party, and he liked to make people laugh. He expressed that he had experienced difficulties in school and has been seriously bullied over the past three years and has had thoughts about taking his life in this connection.

Lucas's factual knowledge about the world around him is a bit below what is expected of boys at his age ${ }^{9}$, i.e., types of knowledge that children in school ordinarily have the opportunity to acquire at that age level. As verbal concept formation and abstract thinking as well as the capacity to be able to move from fact to general rules and principles, Lucas is age-appropriate. His calculating skills, understanding of numbers and his reasoning ability, as well as word understanding, and the ability to express a broad range of thoughts verbally

\footnotetext{
${ }^{5}$ At the 97th percentile level, corresponding to less than 3\% of boys at Lucas' age.

${ }^{6}$ Similarly, on the 97th percentile level corresponding to less than 3\% of boys at Lucas' age.

${ }^{7}$ Corresponding to less than $4 \%$ of boys at Lucas' age.

${ }^{8}$ Corresponding to less than $12 \%$ of boys at Lucas' age.

${ }^{9}$ Information 8 scale points.
} 
was strongly compromised ${ }^{10}$, while the capacity for practical reasoning and the ability to utilize knowledge in a meaningful way lies within what is expected of boys at Lucas' age. Lucas' ability to recite numbers in a specific order was compromised in relation to the age ${ }^{11}$. Tests that show something about the ability to concentrate, visual organization and long-term memory as well as general intelligence and non-linguistic concept formation are solved in a manner that is far below what is expected of boys at Lucas' age ${ }^{12}$. Meanwhile, Lucas scored way above what is expected in a test ${ }^{13}$ of his ability to plan and understood a situation and worked sequentially. Similarly, Lucas scored above average in a test ${ }^{14}$ of visual synthesis and object formation and the ability to utilize visual feedback lies above average ${ }^{15}$. His capacity to in relation to visuo-motor skills coordination and his processing ability is somewhat slow ${ }^{16}$, while the processing ability in light of perceptual organization is very normal for the age ${ }^{17}$. The short-term memory is also said to be intact ${ }^{18}$.

Intra-psychic level. Lucas did not seem to be very willing to share what he saw. He had some notions and thoughts about friendship and animosity, and murder was strongly presented in his thoughts. Moreover, he did not seem to be interested in the world at large at all ${ }^{19}$. He did not have good function control ${ }^{20}$ and did not know what to do or how to react if he became strained or burdened. This is indicative of his immaturity ${ }^{21}$ and similar to younger children. He had trouble in controlling the way he expressed emotions. He enjoyed emotional stimulation $^{22}$, but it seemed he did not have enough sufficient capacity for emotional involvement ${ }^{23}$. Lucas was no more self-absorbed than normal for his age, so he focused just as much on himself as other children $\mathrm{do}^{24}$. Not much suggests sufficient capacity for self-reflection ${ }^{25}$. His way of processing impressions ${ }^{26}$ and identifying impressions/notions was not so $\operatorname{good}^{27}$, so he would often misunderstand what was actually going on. This also suggested that he lacked flexibility ${ }^{28}$. When he has decided to view the world in a certain way he continued to uphold this view. It seemed as though he used intellectualization as his primary defense ${ }^{29}$. This means that in social situation he ignores the emotional component. This furthermore suggests that he has disturbed conception and a somewhat compromised capacity for emotional involvement ${ }^{30}$. The most disrupted aspect is his way of processing impressions ${ }^{31}$. Meaning, he processed unrealistically and he translated what happened in a bad way and misunderstood things. His conceptions and thoughts about how the world works

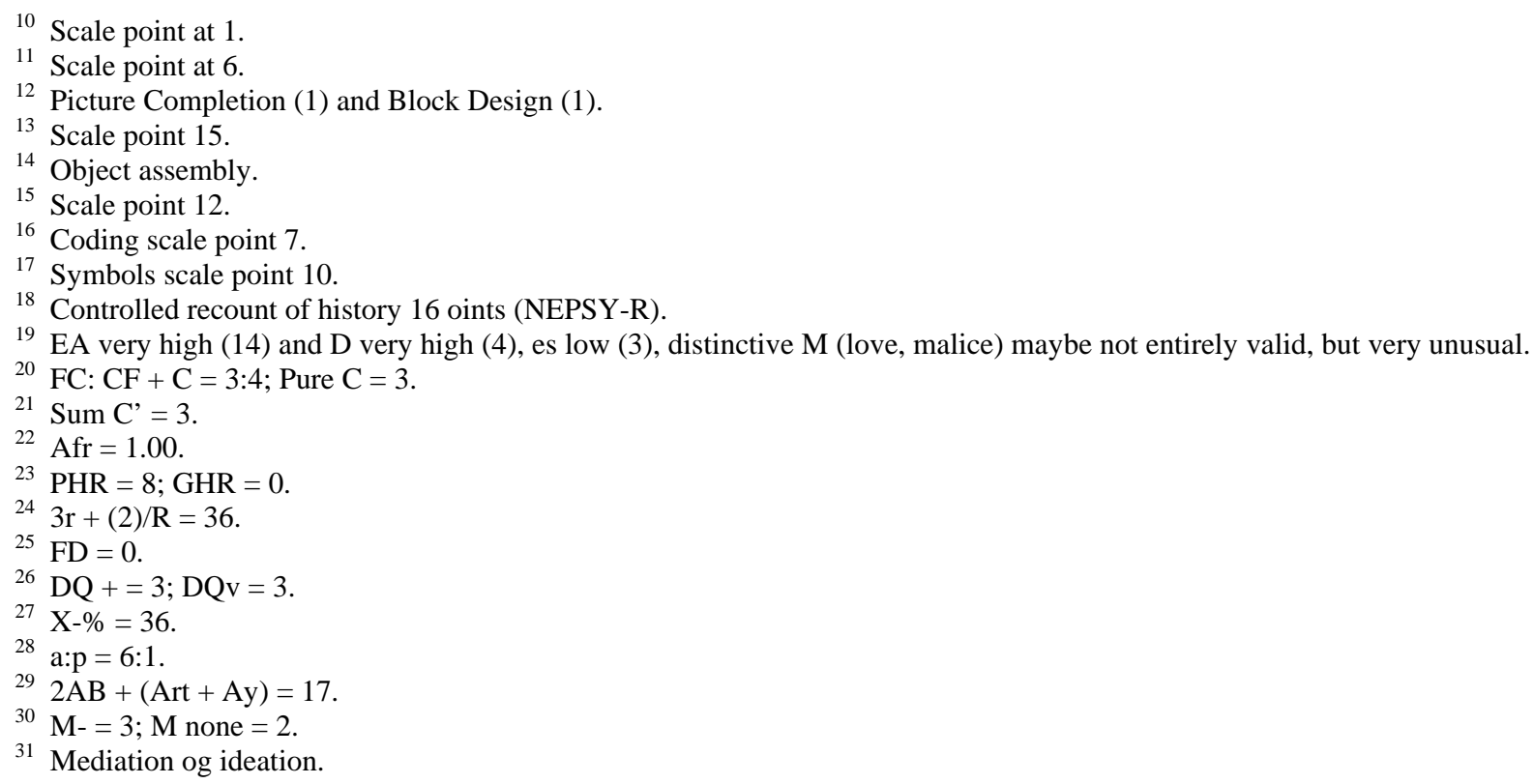


was rather disturbed, and for Lucas, social problems become somatic symptoms. It seems as if ${ }^{32}$ Lucas did not consider him and others as psychological entities with complex characteristics, but he had his own subjective experience of the world around him. People are viewed with a one-dimensional characteristic with emphasis on isolated events, a description of the person's appearance or an interchangeable characterization of the persons. The emotional quality in the representation of people and human relations seems to be characterized by a mildly negative tone ${ }^{33}$ and Lucas' capacity for emotional engagement and investment in relation to others seems to be comprised to some extent ${ }^{34}$. Moral conflicts seem to be recognized, but friendships are thought to be replaceable. Likewise, the capacity, for the causes Lucas attributes to other people's actions, thought and emotions, is to some extent compromised ${ }^{35}$. The reasons for this are attributed to the surroundings and actions (outer S-R explanations with a "black-box" view of the psyche).

Biophysical level. Lucas is an attractive, $185 \mathrm{~cm}$ tall boy, who weighs approximately $75 \mathrm{~kg}$. He is fit and well-build with defined muscles and short blond, curly hair. His general health is good and he showers regularly, takes care of his teeth, makes sure to change his clothes for the occasion (work clothes, running clothes, etc.). His motor-functions are age appropriate. Lucas has complained of several aches various places in his body and consulted a doctor or emergency room several times. Lucas has periodic tics in the form of twitches in the neck.

\section{Strengths and Obstacles in the Personality and Relations}

Figure 6 illustrates an outline of the strengths in the personality and relations. It also provides an overview of the obstacles to developments in the personality and relations, which the care center's personnel have jointly identified.

\begin{tabular}{|c|c|}
\hline $\begin{array}{l}\text { Lucas lives at the care center with a boy of the same age-friend type } \\
\text { relationships—-mutual interests; } \\
\text { The care center has a lot of activity opportunities and recurrent, predictable } \\
\text { activities, predictability, routines; } \\
\text { Environment is a small town with a high tolerance; } \\
\text { Good opportunities for own transport; } \\
\text { Good relations to Lucas' former class in the home environment; } \\
\text { Good relations to Lucas' former professionals in the home environment; } \\
\text { Good school location. }\end{array}$ & $\begin{array}{l}\text { Obstacles in the environment: } \\
\text { Currently there seems to be an } \\
\text { ambivalent relationship between } \\
\text { mother and son which often results in } \\
\text { conflicts and changing previously } \\
\text { arranged agreements; } \\
\text { Currently there are no apparent } \\
\text { obstacles towards development in the } \\
\text { environment. }\end{array}$ \\
\hline $\begin{array}{l}\text { Strengths within the personality: } \\
\text { Good at planning a procedure (sequential thinking); } \\
\text { Being able to work focused and consistent; } \\
\text { Good ability to use visual impressions and convert them to action; } \\
\text { Good sense of humor; } \\
\text { Appreciates justice, fairness; } \\
\text { Expresses responsibility towards agreements; } \\
\text { Has a social competence which entails that he is able to appeal and charm his } \\
\text { surroundings; } \\
\text { Be kind and helpful in situations where the aim is known; } \\
\text { Likes emotional stimulation in social relations; } \\
\text { Eats well and is body-conscious. }\end{array}$ & \begin{tabular}{|l|} 
Obstacles within the personality: \\
Lacks control abilities in open social \\
situations with severe affect outbursts \\
as a result; \\
Processes impressions in such a way \\
that he misunderstands things and his \\
way of perceiving the world is disturbed \\
Summarizes social problems with \\
daily complaints over aches and pains; \\
Compromised capacity towards \\
emotional involvement; \\
Poor capacity of self-reflection.
\end{tabular} \\
\hline
\end{tabular}

Figure 6. Obstacles and strengths in the environment and personality.

\footnotetext{
${ }^{32}$ Complexity of Representations of People, mean $=2.1$.

33 Affect-tone of Relationship Paradigms mean = 3.1.

${ }^{34}$ Capacity for Emotional Investment in Relationships mean $=2.1$.

${ }^{35}$ Understanding of Social Causality mean $=2.0$.
} 


\section{Assessment and Interventions}

Lucas is a harmonious 15-year-old boy, with an age appropriate development and a fit build. Lucas has humor and is whimsical. He appreciates fairness and justice. Lucas seemed to process his impressions of his surroundings in such a way so that he misunderstands things, and his thoughts about how the world works are slightly disturbed. The ability to be empathetic also seems to be compromised in such a way that he saw other people's actions more as reactions to relations in the surroundings than as a consequence of people's internal circumstances. Lucas is not unintelligent, but his ability to understand numbers, words and reasoning and express a broad spectrum of thoughts verbally is strongly compromised. He does not possess an adequate control function and he becomes very emotional under pressure. Lucas is a boy characterized by anxiety and he is in an anti-social personality disorder development (Bleiberg, 2001; Kernberg, 1996; Kernberg et al., 2000; Millon, 1996, 1999; Millon \& Davis, 1996). He has experienced rejection and bullying and carries around a number of untreated negative impressions, and currently seems to suffer from summarization of his social difficulties.

The interventions are as follows:

(1) Lucas, needs to be confronted with how he comes across to other people, for example his "stories", which his surroundings do not believe him, hereby examining what the message is when he told these stories;

(2) Examining which form of feedback Lucas needs when he exaggerates and repeatedly tells others about his plans and activities;

(3) Lucas is to some extent foreclosed on the "self-polarity" (Millon, 1999; Millon \& Davis, 1996; Millon, Simonsen, Birket-Smith, \& Davis, 1998) meaning that he is more focused on his own needs, but not so much on others. He, thus, needs to create balance in the give-and-take relationships, and he needs to figure out how others think and feel;

(4) Mediating intervention when Lucas processes impressions and misunderstands things. This needs to ask questions that aim towards alternative interpretations and understandings or test other interpretations of what is going on, both in relations to emotions and ways of thinking;

(5) Working on the negative thoughts from his past that produce anxiety and are causing summarization;

(6) Comforting building settings and relations;

(7) Focusing on the advantages of responsible behavior;

(8) Supporting Lucas' initiatives towards medical discussion and assessment of the somatic symptoms. Regular professional massage outside the care center;

(9) Exploring his capacity for emotional investment in relationships;

(10) Inviting friends, family, acquaintances and relatives to the care center;

(11) Supplying him with challenges in relation to his strengths with the aim to develop self-esteem;

(12) Cooperating with his mother.

\section{The Theory- and Evidence- Based Psycho-relational Assessment and Intervention Model PRAIM and Practice-Based Evidence and Effect Measurement}

During a treatment conference at the care center, the historical, relational and personality structural and functional date were presented, discussed and put into theoretical perspective (Kernberg, 1996; Kernberg et al., 2000; Millon, 1999; Millon \& Davis, 1996; Westen, 2000) with 11 intervention suggestions. As the footnotes 
indicate, this preliminary assessment has been supplemented with a series of tests: Rorschach Inkblot Test (Exner, 2003), TAT (Westen, 1991), WISC-III (Achenbach, 2009), NEPSY (Developmental Neuropsychological Assessment) (Korkman et al., 1998), so that, besides the qualitative data, the data can also be measured quantitatively, i.e., to what extent a positive development has taken place by preparation of assessment No. 2. By comparing data at the behavioral level with data at the intra-psychic level, one can gain an impression about whether an eventual positive development is anchored in the deeper parts of the personality or merely an expression of superficial adjustment.

The theory- and evidence- based psycho-relational assessment and intervention model PRAIM can also be supplied with practice-based evidence and effect measurement to figure out where an eventual effect stems from. There is a copious amount of literature in psycho-therapeutic effect research (Lambert, 1992; Lambert \& Bergin, 1994) that shows that only $15 \%$ of the effect comes from the intervention itself, whilst $30 \%$ originates from alliance factors and $40 \%$ from client factors, whether the client can use the intervention he/she is exposed to in their development. The last $15 \%$ originates from anticipation factors, i.e., whether the therapist expects a positive development.

Based on this, Lucas' care center used so-called analog rating scales ( Duncan et al., 2003; Duncan, Sparks, Miller, Bohanske, \& Claud, 2007; Miller \& Duncan, 2004a), which measures where the majority (70\%) of the treatment effect is said to stem from (Lambert \& Bergin, 1994), and which takes a relatively short amount of time (one minute) to be used and which is just as reliable as more time-consuming rating scales (Duncan et al., 2006). Two scales were used. One that measures, to what extent, the children and adolescents find the interventions they are exposed to during their development process useful, and one that measures how they develop during their stay (Miller, Duncan, Brown, Sparks, \& Claud, 2003). To strengthen these instruments, computer-based programs have been developed to calculate the effect size (Miller \& Duncan, 2004b). The idea is that in connection with assessment No. 1, a series of interventions are devised, which are then put into practice where after Duncan and Miller's rating scales measure the practice-based evidence. Later on, assessment No. 2 can be devised, so that an overall picture of the treatment effect can be developed—whether there is an effect and where it stems from, so it is possible to measure the effect of the initiated interventions.

\section{References}

Achenbach, T. (2009). The ASEBA (Achenbach System of Emperically Based Assessment): Development, findings, theory and applications. Burlington, V. T.: University of Vermont.

Bleiberg, E. (2001). Treating personality disorders in children and adolescents. New York: The Guilford Press.

Brooks, B. L., Sherman, E. M., \& Strauss, E. (2010). NEPSY-II: A developmental neuropsychological assessment, second edition. Child Neuropsychology, 16, 80-101.

Duncan, B., Sparks, J., Miller, S., Bohanske, R., \& Claud, D. (2006). Giving youth a voice: A preliminary study of the realibility and validity of a brief outcome measures for children. Journal of Brief Therapy, 5(2), 71-88.

Duncan, B. L., Miller, S. D., Sparks, J. A., Claud, D. A., Reynolds, L. R., ..., Brown, J. (2003). The session rating scale: Preliminary psychometric properties of a "working” alliance measure. Journal of Brief Therapy, 3(1), 3-21.

Duncan, B. L., Sparks, J. A., Miller, S. D., Bohanske, R. T., \& Claud, D. A. (2007). Giving youth a voice: A preliminary study of reliability and validity of a brief outcome measure for children, adolescents and caretakers. Journal of Brief Therapy, 5(2), 71-88.

Erikson, E. (1950/1963). Childhood and society. New York: W. W. Norton.

Exner, J. E. (2003). The Rorschach-A Comprehensive System (4th ed., Vol. 1). New Jersey: John Wiley \& Sons.

Glasser, W., \& Wubbolding, R. E. (1995). Reality therapi. In R. J. Corsini, \& D. Wedding (Eds.), Current psychotherapies. Illinois, F. E.: Peacock Publishers, Inc.. 
Kernberg, O. F. (1996). A psychoanalytic theory of personality disorders. In J. F. Clarkin, \& M. F. Lenzenweger (Eds.), Major theories of personality disorder. New York: The Guilford Press.

Kernberg, P. F., Weiner, A. S., \& Bardenstein, K. K. (2000). Personality disorders in children and adolescents. New York: Basic Books.

Klein, M. (1990). Misundelse og taknemmelighed. København: Hans Reitzels Forlag.

Kohut, H. (1971). The analysis of the self. New York: The International Universities Press.

Kohut, H. (1977). The restoration of the self. Madison, Connecticut: International Universities Press, Inc..

Lambert, M. J. (1992). Psychotherapy outcome research-Implications for integrative and eclectic therapists. In J. C. Norcross, \& M. R. Goldfried (Eds.), Handbook of psychotherapy integration (pp. 94-129). New York: Basic Books.

Lambert, M. J., \& Bergin, A. E. (1994). The effectiveness of psychotherapy. In A. E. Bergin, \& S. L. Garfield (Eds.), Handbook of psychotherapy and behavior change (4th ed., pp. 143-189). New York: Wiley.

Mahler, M. S. (1975/2000). The psychological birth of the human infant. New York: Basic Books.

Miller, S. D., \& Duncan, B. L. (2004a). The outcome and session rating scales-Administration and scoring manual. Chicago: Institute for the Study of Therapeutic Change.

Miller, S. D., \& Duncan, B. L. (2004b). A.S.I.S.T. (Version 2.07). Chicago: Institute for the Study of Therapeutic Change.

Miller, S. D., Duncan, B. L., Brown, J., Sparks, J. A., \& Claud, D. A. (2003). The outcome rating scale: A preliminary study of the reliability, validity and feasibility of a brief visual analogue measure. Journal of Brief Therapy, 2(2), 91-100.

Millon, T. (1996). Personality and psychopathology. New York: John Wiley \& Sons.

Millon, T. (1999). Personality-guided therapy. New York: John Wilay \& Sons.

Millon, T., \& Davis, R. (1996). Disorders of personality DSM-IV and beyond. New York: John Wiley \& Sons.

Millon, T., Simonsen, E., Birket-Smith, M., \& Davis, R. (Eds.). (1998). Psychopathy-Antisocial, criminal and violent behavior. New York: The Guilford Press.

Nissen, P. (2007). Assessment- and Intervention Guide - Theory- and evidence-based intervention, practice-based evidence and outcome measurement. København: Dansk Psykologisk Forlag.

Pretzer, J., \& Beck, A. T. (1996). A cognitive theory of personality disorders. In J. Clarkin, \& M. Lenzenweger (Eds.), Major theories of personality disorder. New York: The Guilford Press.

Raskin, N. J., \& Rogers, C. R. (1995). Person-centered therapy. In R. J. Corsini, \& D. Wedding (Eds.), Current psychotherapies. Illinois, F. E.: Peacock, Inc..

Reichler, R., \& Lee, E. (1987). Overview of biomedical issues in autism. In E. Shopler, \& G. Mesibov (Eds.), Neurobiological issues in autism (pp. 13-41). New York: Plenum.

Sameroff, A. J. (2000). Dialectical processes in developmental psychopathology. In A. J. Sameroff, M. Lewis, \& S. M. Miller (Eds.), Handbook of developmental psychopathology. New York: Kluwer Academic/Plenum Publishers.

Sroufe, L. A., Duggal, S., Weinfield, N., \& Carlson, E. (2000). Relationships, development and psychopathology. In A. J. Sameroff, M. Lewis, \& S. M. Miller (Eds.), Handbook of developmental psychopathology. New York: Kluwer Academic/Plenum Publishers.

Stern, D. N. (1985). The Interpersonal world of the infant. New York: Basic Books.

Wechsler, D. (2003). The WISC-IV technical and interpretive manual. San Antonio, T. X.: Psychological Corporation.

Westen, D. (1991). Clinical assessment of object relations using the TAT. Journal of Personality Assessment, 56(1), 56-74.

Westen, D. (2000). Integrative psychotherapy: Integrating psychodynamic and cognitive-behavioral theory and technique. In C. R. Snyder, \& R. E. Ingram (Eds.), Handbook of psychological change. New York: John Wiley \& Sons.

Westh, F., Ferrer, C., Prieler, J., \& Hartmann, P. (in press). Objectively measuring parenting style: The construction, development and psychometric properties of the parents' preference test, PPT. Scan Journal of Psychology. 